RU Реализация творческой активности

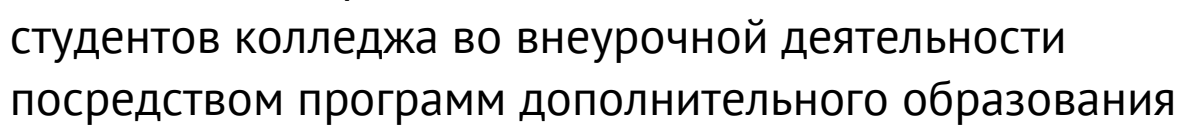

Рынкова С. А.

Аннотация. Цель исследования - раскрыть основные аспекты реализации внеурочной деятельности обучающихся колледжа, организуемой в колледже в рамках программ дополнительного образования. В статье актуализируется значение внеурочной деятельности для социализации и трудоустройства выпускника колледжа; определяется содержание понятия «творческая активность»; отмечается необходимость индивидуализации учебного процесса, исходя из природных склонностей и интересов обучающихся. Научная новизна работы заключается в разработке системы внеурочной деятельности в образовательной организации среднего профессионального образования, в рамках которой реализуется творческая активность как студентов, так и педагогов колледжа. В результате исследования выявлено, что мероприятия внеурочной деятельности включают в себя компоненты, интегрирующие усилия по построению системы дополнительного образования и обеспечивающие триединство обучения, воспитания и развития.

\title{
EN Realization of College Students' Creativity through Extra-Curriculum Activity within Additional Educational Programs
}

\section{Rynkova S. A.}

\begin{abstract}
The paper aims to reveal the basic aspects of college students' extra-curriculum activity within additional educational programs. The article emphasizes the role of extra-curriculum activity in a college graduate's socialization and career development. The author reveals the content of the notion "creative activity", justifies the necessity of the personally oriented educational approach that takes into account a learner's natural abilities and interests. Scientific originality of the study includes developing a system of extra-curriculum activities promoting realization of college students' and teachers' creative potential. As a result, it is shown that extra-curriculum activities promote development of the additional education system and ensure integrity of pedagogical process that encompasses education, upbringing and personal development.
\end{abstract}

\section{Введение}

Актуальность темы исследования обусловлена значением внеурочной деятельности для социализации и трудоустройства выпускника колледжа. Формирование творческой личности является целью непрерывного индивидуализированного образования, способствующего созданию инновационной социально ориентированной экономики [8]. Анализ нормативно-правовой и программной документации федерального и регионального уровней показал, что федеральные государственные стандарты СПО не предусматривают формирования у обучающихся компетенции «креативность» или «творческое мышление», тогда как социальный заказ на формирование творческой личности декларируется государством [20]. Между тем работодатели, принимающие на производственную практику, а затем и на постоянную работу обучающихся колледжей, обращают особое внимание как на сформированность профессиональных компетенций, так и универсальных: принятие решений в нестандартной ситуации, гибкость, оригинальность, дивергентное мышление, которые являются составными частями креативности. Таким образом, проблема нехватки выпускников, обладающих творческим мышлением, может решиться созданием благоприятной развивающей образовательной среды в рамках организации внеурочной деятельности посредством программ дополнительного образования. 
Для достижения поставленной цели необходимо решить следующие задачи:

- раскрыть содержание термина «творческая активность» и проанализировать исследования, посвященные данной теме;

- показать изученность проблемы дополнительного образования в организациях среднего профессионального образования;

- представить результативность внеурочной деятельность через реализацию дополнительных образовательных программ.

В статье используются следующие методы исследования: теоретико-методологический анализ нормативных документов, научной литературы, научно-методических исследований, эмпирический - анализ анкетирования студентов, результатов деятельности участников образовательного процесса.

Теоретической базой послужили труды Н. В. Кузьминой, Л. М. Митиной, А. К. Марковой, В. И. Загвязинского, В. А. Кан-Калика, в работах которых рассматривается творческая деятельность педагога как неотъемлемая часть педагогического процесса [5; 7; 9; 13; 14].

Практическая значимость исследования заключается в возможности использования опыта организации внеурочной деятельности другими образовательными организациями среднего профессионального образования.

\section{Содержание термина «творческая активность»}

Анализ современных работ по исследуемой проблеме показал, что основное внимание ученых после 2010 г. было направлено на создание особых организационных или педагогических условий для формирования и развития творческой активности (В. В. Марков) [12], творческого потенциала (И. В. Беседина, В. И. Буренина, М. Л. Субочева) [2; 4; 18], творческого мышления обучающихся (Е. В. Чистюлина) [21], проектирования творческой деятельности будущих специалистов (В. В. Зилева) [10], стимулирования технического творчества обучающихся (Т. И. Улитина) [19], совершенствования педагогов среднего образования (Г. О. Курбонов) [10].

Краткий педагогический словарь определяет творческую активность как «стремление ученика к теоретическому осмыслению знаний, самостоятельному поиску решения проблем, проявление познавательных интересов. Стимулирование творческой активности личности требует от педагогов создания таких условий обучения, которые вызывают интерес к учению, потребность к знанию и в конечном итоге их сознательное усвоение» [16, с. 62]. Творческая активность, по мнению В. С. Безруковой, - это «свойство личности, проявляющееся в деятельности и общении как оригинальность, созидательность, новизна. Творческая активность это способность личности инициативно и самостоятельно находить «зоны поиска», ставить задачи, выделять принципы, лежащие в основе тех или иных конструкций, явлений, действий, переносить знания, навыки и умения из одной области в другую» [1, с. 793]. Следовательно, такой вид активности обусловлен самоанализом и рефлексией. Стимулом к творческой деятельности может являться проблемная ситуация, которая разрешается нетрадиционным, нестандартным, оригинальным способом при наличии гибкости мышления, критического и ассоциативного мышления, цельности восприятия [2].

\section{Степень изученности проблемы дополнительного образования} в образовательных организациях среднего профессионального образования

Внеурочная деятельность в колледже в значительной мере реализуется в рамках дополнительных образовательных программ. Дополнительное образование определяется Федеральным законом «Об образовании в Российской Федерации» от 26.12.2012 № 273-Ф3 как «вид образования, который направлен на всестороннее удовлетворение образовательных потребностей человека в интеллектуальном, духовно-нравственном, физическом и (или) профессиональном совершенствовании и не сопровождается повышением уровня образования» [15, с. 5]. Особо подчеркиваются индивидуальный подход и учет возрастных особенностей при получении дополнительного образования и направленность на организацию свободного времени обучающихся. Важно, что дополнительное образование обеспечивает мобильность, гибкость, адаптацию к меняющимся условиям в обществе, возможность профессиональной ориентации подростков, что облегчает впоследствии получение профессионального опыта.

Тема развития дополнительного образования и внеурочной деятельности в учреждениях среднего профессионального образования недостаточно изучена, несмотря на то, что дополнительное образование обучающихся всегда было и остается необходимым компонентом образовательного процесса в профессиональных образовательных организациях. Однако существуют работы, на которые следует обратить особое внимание. В первую очередь это исследование Е. Л. Бойко и А. Л. Пикиной, в котором актуализируются вопросы использования ресурсов дополнительного образования. Авторы разработали модель развития профессиональных учреждений за счет использования потенциала дополнительного образования и показали, что интеграция профессионального и дополнительного образования приводит к качественным изменениям в образовательной деятельности учреждения [3].

Заслуживает внимания и мнение С. О. Лукашевой, согласно которому активное развитие дополнительного образования в колледже определяет развитие воспитательной системы образовательного учреждения 
и способствует сотрудничеству студентов и преподавателей, помогает студентам развивать лидерские качества, работать в команде, принимать решения и нести за них ответственность [11].

Таким образом, степень изученности проблемы показывает, что вопрос реализации творческой активности студентов и педагогов колледжа во внеурочной деятельности, будучи актуальным в контексте стремительного развития среднего профессионального образования в последние годы, недостаточно исследован и требует отдельного рассмотрения.

\section{Характер внеурочной деятельности студентов Новосибирского автотранспортного колледжа посредством дополнительных образовательных программ}

Для формирования и развития творческих способностей у студентов, обучающихся на специальностях укрупненной группы 23.00.00 Техника и технологии наземного транспорта, в Новосибирском автотранспортном колледже проводится целенаправленная системная работа, которая отражена в системе внеурочной деятельности и дополнительного образования. В колледже создаются условия по сопровождению преподавателей и мастеров производственного обучения для того, чтобы творческий потенциал и педагога, и обучающихся мог максимально раскрыться. В процессе внеурочной деятельности углубляются и расширяются общие и профессиональные компетенции, развиваются личностные и метапредметные компетенции студентов, духовная сфера, интеллектуальные и творческие способности.

Рассмотрим основные взаимосвязанные компоненты системы внеурочной деятельности в Новосибирском автотранспортном колледже, выделяемые на основе воспитательной системы Е. Н. Степанова [17, с. 38]:

1. Индивидуально-групповой компонент, представляет собой социальное партнерство обучающихся и преподавателей, наставников, администрации и сотрудников колледжа, а также отражает индивидуальный подход к каждому студенту с учетом их особенностей, интересов и задатков.

2. Ценностно-ориентационный компонент. Задача образования (и основного, и дополнительного) - способствовать формированию ценностных ориентаций обучающихся, которые определяют стержень личности, оказывают влияние на социальную активность, общий подход к миру и самому себе, придают смысл и направление общественной позиции личности, приводят к осознанию значимости получаемой профессии.

3. Функционально-деятельностный компонент. Включает в себя системообразующий вид деятельности, формы и методы организации совместной деятельности и общения. Деятельность может быть проектная, конструкторская, познавательная, социологическая, агитационная, исследовательская, коммуникативная, творческая и др.

4. Компетентностный компонент. Все программы направлены на формирование и развитие общих (универсальных) и (или) профессиональных компетенций, а также так называемых софт-компетенций - креативности, коммуникативных навыков, компьютерной и технической грамотности, межличностных навыков, адаптивности, исследовательских навыков, навыков управления проектами и других.

5. Диагностико-результативный компонент. Включает в себя и результаты по каждой программе дополнительного образования, и диагностические исследования и статистические данные об индивидуальнопсихологических особенностях студента, мониторинги, необходимые для построения индивидуальной траектории развития обучающихся.

В целом в колледже созданы организационно-педагогические условия для реализации непрерывного образования как обучающихся, так и преподавателей: семинары, мастер-классы, открытые уроки, круглые столы. Для обучения педагогов используются активные методы (тренинги, мастер-классы, беседы, дискуссии, практикумы, интерактивные лекции, вебинары, семинары и др.), новейшие дистанционные технологии для организации занятий и контроля освоения компетенций: Google, Mentimeter, Kahoot, Quizizz, Canva, LearningApps, OnlineTestPad и др. Преподаватели получают неформальное и информальное образование в соответствии с разработанным в сотрудничестве с методической службой индивидуальным маршрутом профессионального развития.

Внеурочная деятельность в Новосибирском автотранспортном колледже построена на основе компетентностного подхода, который акцентирует внимание на формировании у студентов компетенций, обеспечивающих в дальнейшем возможность успешной социализации и трудоустройства. Кроме общих и профессиональных компетенций, требуемых федеральными государственными образовательными стандартами, в процессе обучения студенты развивают так называемые софт-компетенции: креативность, критическое мышление, социальные компетенции - и используют их при решении практических задач в условиях, максимально приближенных к реальности, например при участии в чемпионатах «Молодые профессионалы» и демонстрационном экзамене по компетенциям «Экспедирование грузов» и «Ремонт и обслуживание легковых автомобилей».

Обучение по дополнительным образовательным программам различной направленности осуществляется в колледже параллельно основной образовательной программе и охватывает по разным направлениям от 10 до 100\% обучающихся. Программы предоставляют студентам возможность реализовать свой творческий и интеллектуальный потенциал в различных сферах - и гуманитарной, и технической, и спортивной. По данным анкетирования, проведенного в 2020 г. среди 870 студентов 1-4 курсов, 27\% обучающихся Новосибирского автотранспортного колледжа проводят свой досуг в сторонних организациях, таких как фитнес-клубы, дома творчества, добровольные молодежные дружины, школы искусств. Начиная с 3 курса, многие студенты устраиваются в профильные организации по специальности, таким образом, творческий досуг заменяется профессиональным трудом. В мероприятиях внеурочной деятельности колледжа охвачено более 80\% обучающихся. 
Таким образом, количество студентов, не охваченных досуговыми мероприятиями, дополнительным образованием общеразвивающего характера, объясняется ранней профориентацией, стремлением обучающихся трудоустроиться по получаемой специальности во время обучения в колледже.

\section{Программы дополнительного образования общеразвивающего характера для студентов Новосибирского автотранспортного колледжа}

В соответствии с нормативными документами внеурочная деятельность в значительной мере осуществляется в соответствии с программами дополнительного образования общеразвивающего характера: спортивно-технической, спортивной, экологической, гражданско-патриотической, психолого-педагогической и здоровьесберегающей, социально-культурной направленностей. Остановимся лишь на некоторых, связанных с будущей профессиональной деятельностью обучающихся.

Так, программа секции автомобильного моделирования «Сделай сам» нацелена на работу со студентами, направленную на проектирование, изготовление и техническое обслуживание транспортных средств, начиная от выбора проекта до готовой, действующей модели, где все детали сделаны своими руками, собраны и смонтированы в единую конструкцию. В результате у обучающихся формируется понимание ценности и социальной значимости своей профессии, развивается устойчивый интерес в достижении запланированного результата. Работая в режиме проекта, студенты учатся целеполаганию, эффективному взаимодействию в команде, ответственности за работу членов команды, поиску профессиональных решений в различных ситуациях, самообразованию, умению ценить свой и чужой труд.

Кроме того, во время работы секции обучающиеся на практике осваивают профессиональные компетенции, соответствующие всем основным видам деятельности, обозначенным во ФГОС СПО, а также софт-компетенции, в том числе развивают креативность - при конструировании объекта изготовления, его отделке и т.д. В данном случае уместно говорить о факте «сотворчества» преподавателя и обучающихся, когда в ситуации непосредственного взаимодействия открывается возможность для решения нестандартных задач, создается особая эвристическая атмосфера, способствующая раскрытию творческого потенциала ребят и самого педагога [7, с. 53-55]. В 2019 г. творческая группа секции автомобильного моделирования «Сделай сам» стала победителем областного конкурса «Кубок конструкторов», а руководитель секции стал призером областного конкурса «Лучшее творческое объединение».

С 2006 г. в Новосибирском автотранспортном колледже работает секция автомобильного многоборья. Актуальность данной программы обусловлена реальной возможностью эффективного вовлечения подростков в технические виды спорта и раскрытия их творческого потенциала. Автомногоборье в современных условиях развития технического творчества рассматривается как эффективный инструмент подготовки ответственных водителей и пешеходов. Стремительное увеличение количества автомобилей на дорогах привело к увеличению числа дорожно-транспортных происшествий. Одной из основных причин такого роста является низкий уровень подготовки водителей. Автомногоборье позволяет не только овладеть техникой вождения автомобиля, но и в совершенстве знать правила дорожного движения.

За почти 15 лет работы через секцию прошло более 200 человек. Обучающиеся принимали участие в соревнованиях в различных городах России: Анапа, Казань, Владимир, Курск, Ейск, Санкт-Петербург, Смоленск, Пермь, Омск, Шадринск, Челябинск, Карасук, Черепаново, Маслянино, Ордынское. Студенты образовательных организаций демонстрируют свои навыки вождения, знания правил дорожного движения и стрельбы из пневматической винтовки. География соревнований растёт с каждым годом, это говорит о популярности автомногоборья среди молодёжи. Колледж уже много лет является площадкой для проведения Регионального чемпионата по автомобильному многоборью. В 2018 г. в чемпионате приняли участие 13 команд - 39 обучающихся из различных регионов: Новосибирской, Иркутской, Кемеровской областей, Красноярского края, Республики Тыва.

«Введение в профессию» - курс профессионального самоопределения для первокурсников - проводится под руководством преподавателя технического обслуживания автомобилей и мастера производственного обучения. Обучающиеся сначала узнают технику безопасности работы с инструментами, устройство двигателя и других узлов, затем производят демонтаж, дефектовку и сборку, при необходимости замену неисправных узлов автомобиля. Такая профориентация способствует дальнейшей мотивации студентов при изучении дисциплин профессионального цикла, а также выявляет одаренных обучающихся для последующей подготовки к чемпионату «Молодые профессионалы (Ворлдскиллс Россия)» Новосибирской области. Студенты Новосибирского автотранспортного колледжа неоднократно становились победителями и призерами данного чемпионата благодаря тому, что в ходе внеурочной подготовки имели возможность тренировать навыки решения нестандартных задач, творчески разработанных преподавателями и мастерами производственного обучения.

Проект «Воспитание экологической культуры у студентов Новосибирского автотранспортного колледжа» осуществляется в период с 2018 г. по 2022 г. и направлен на формирование экологически сознательного и образованного гражданина. Цель проекта - формирование высокого уровня экологической образованности и культуры не менее чем у 70\% обучающихся в колледже к 1 июня 2022 г. В соответствии с Экологической доктриной РФ [22] экологическое воспитание, образование и просвещение признаны одним из средств реализации государственной экологической политики нашей страны. Способность человека оценивать результаты своей деятельности с точки зрения воздействия на природу - это экологическое мышление, которое можно сформировать 
только в системе непрерывного экологического воспитания и образования. В проекте приводятся статистические исследования, проведенные в колледже на этапе инициации, показатели проекта и их значения по годам, ожидаемые результаты проекта, реестр заинтересованных сторон, план-график с перечислением направлений и мероприятий, модель функционирования результатов проекта, реестр рисков и возможностей, мероприятия, направленные на формирование экологической культуры, в том числе путем развития творческих способностей у обучающихся. Например, студенты колледжа стали участниками, призерами и победителями Межрегиональной студенческой научно-практической конференции «Косыгинские чтения», регионального конкурса «Серебряный стриж - Начни с дома твоего», экологических чтений «Сибирь - край заповедный», экологической викторины «Экологический след», посвященной проблеме чрезмерного потребления природных ресурсов, конкурса творческих работ «Отходы в дело», областной научно-практической конференции «Профессия. Экология. Культура» и многих других городских, областных и всероссийских мероприятий.

Программа патриотического воспитания «Я - гражданин России» нацелена на совершенствование системы гражданско-патриотического воспитания, обеспечивающего формирование у обучающихся патриотического сознания, гражданских компетенций личности, верности традициям колледжа, готовности к выполнению профессиональных обязанностей, а также на развитие творческих способностей как у обучающихся, так и преподавателей колледжа. Приведем лишь отдельные достижения студентов, участвующих в мероприятиях по данному направлению: за последние 5 лет обучающиеся становились лауреатами и дипломантами таких областных конкурсов и фестивалей, как «Я вхожу в мир искусств» в номинациях «Истоки подвига», «Краеведение», фотоконкурс «Мир, в котором я живу» в номинации «Поклонимся далеким тем годам», студенческая научно-практическая конференция «Техновектор», социальный проект «Гражданином быть обязан», областной музейный урок «Во имя долга...», посвященный увековечиванию памяти выпускников образовательных учреждений, погибших при исполнении служебных обязанностей, с участием профессиональных образовательных учреждений Новосибирской области, областной фестиваль национальных культур «Мы вместе» и мн. др. Также студенты ежегодно участвуют в акциях «Свеча памяти», «Георгиевская ленточка», в фестивале-конкурсе патриотической песни «Солдат войны не выбирает», в народном шествии «Бессмертный полк».

Таким образом, при реализации программ дополнительного образования в рамках внеурочной деятельности обучающиеся колледжа имеют возможность реализовывать творческую активность, которая пригодится в их будущей профессии. Внеурочная деятельность в колледже представляет собой систему, направленную на формирование и развитие творческой активности педагога и студента в сферах технического творчества, автомобильного многоборья, профессиональной ориентации, экологической культуры и патриотического сознания.

\section{Заключение}

В результате теоретико-методологического анализа научной литературы, посвященной проблеме творческой активности, выявлено, что известные исследователи подчеркивали необходимость творческого подхода к учебному процессу, а творческая активность педагога является одной из неотъемлемых профессиональных характеристик. При этом установлено противоречие между запросом работодателей и отсутствием требований федеральных государственных стандартов среднего профессионального образования к усвоению будущими выпускниками профессиональных образовательных организаций компетенций творческой направленности.

Творческая активность преподавателей и студентов колледжа в значительной степени осуществляется в рамках внеурочной деятельности при реализации дополнительных образовательных программ, направленных на формирование и развитие творческих способностей студентов, удовлетворение их индивидуальных потребностей в интеллектуальном и нравственном совершенствовании, формирование культуры здорового образа жизни, организацию их свободного времени, обеспечение адаптации к жизни в обществе, профессиональную ориентацию.

Организация внеурочной деятельности студентов колледжа включает в себя компоненты, интегрирующие усилия по построению системы дополнительного образования и обеспечивающие триединство обучения, воспитания и развития. Таким образом, студенты имеют возможность формировать умения, способности, опыт и личностные характеристики, которые в будущем будут использованы в их профессиональной деятельности.

Перспективы дальнейшего исследования состоят в разработке модели системы дополнительного образования колледжа и программ работы с одаренными студентами по направлению подготовки к чемпионатам профессионального мастерства - «Молодые профессионалы» и региональному этапу Всероссийской олимпиады профессионального мастерства по укрупненной группе специальностей 23.00.00 Техника и технологии наземного транспорта. Программы будут нацелены на создание благоприятных организационно-педагогических условий для развития профессиональных, общих (универсальных) и софт-компетенций обучающихся.

\section{Источники | References}

1. Безрукова В. С. Основы духовной культуры (энциклопедический словарь педагога). Екатеринбург: Деловая книга, 2000. 937 с.

2. Беседина И. В. Развитие творческого потенциала будущих архитекторов в профессиональном образовании: дисс. ... к. пед. н. Оренбург, 2015. 221 с. 
3. Бойко Е. Л., Пикина А. Л. Интеграция дополнительного и профессионального образования как фактор развития учреждений сферы начального профессионального образования // Педагогика. 2008. № 3 (56). С. 58-66.

4. Буренина В. И. Развитие творческого потенциала преподавателя технического вуза в системе повышения квалификации: дисс. .... к. пед. н. Самара, 2018. 222 с.

5. Загвязинский В. И. Педагогическое творчество учителя. М.: Педагогика, 1987.160 с.

6. Зилева В. В. Подготовка будущих специалистов к проектированию творческой деятельности: дисс. .... к. пед. н. Кемерово, 2010. 204 с.

7. Кан-Калик В. А., Никандров Н. Д. Педагогическое творчество. М.: Педагогика, 1990. 144 с.

8. Концепция долгосрочного социально-экономического развития Российской Федерации до 2020 г. [Электронный ресурс]: утверждена распоряжением Правительства Российской Федерации от 17 ноября 2008 г. № 1662-p. URL: https://docs.cntd.ru/document/902130343 (дата обращения: 17.06.2021).

9. Кузьмина Н. В. Способности, одаренность, талант учителя. Л.: Знание, 1985. 32 с.

10. Курбонов Г. О. Теоретические основы профессионально-творческого развития педагога в системе повышения квалификации: дисс. ... к. пед. н. Душанбе, 2018. 150 с.

11. Лукашева С. О. Дополнительное образование как системоразвивающий компонент воспитательной системы колледжа // Казанский педагогический журнал. 2010. № 2. С. 134-139.

12. Марков В. В. Организационно-педагогические условия развития творческой активности учащихся профессионального лицея: дисс. ... к. пед. н. СПб., 2006. 190 с.

13. Маркова А. К. Психология профессионализма. М.: Международный гуманитарный фонд «Знание», 1996. 312 с.

14. Митина Л. М. Психология труда и профессионального развития учителя. М.: Академия, 2004. 320 с.

15. Об образовании в Российской Федерации: Федеральный закон. М.: Проспект, 2020. 224 с.

16. Рындак В. Г. Творчество: краткий педагогический словарь: учебно-методическое пособие. М.: Педагогический вестник, 2001. 84 с.

17. Системная организация процесса воспитания детей: методическое пособие / под ред. Е. Н. Степанова. Псков: ПОИПКРО, 2017. 88 с.

18. Субочева М. Л. Развитие творческого потенциала личности педагога колледжа в системе постдипломного образования как фактор повышения эффективности обучения: монография. М.: Спутник+, 2013. 89 с.

19. Улитина Т. И. Педагогическое стимулирование технического творчества студентов профессиональной образовательной организации: дисс. ... к. пед. н. Челябинск, 2016. 208 с.

20. Федеральный государственный образовательный стандарт среднего профессионального образования по специальности 23.02.01 Организация перевозок и управление на транспорте (по видам) [Электронный ресурс]: утвержден Приказом Министерства образования и науки Российской Федерации от 24 апреля 2014 г. URL: https://edu.ru/documents/view/58471/(дата обращения: 17.06.2021).

21. Чистюлина Е. В. Развитие творческого мышления студентов университета на занятиях иностранного языка: дисс. ... к. пед. н. Магнитогорск, 2010. 175 с.

22. Экологическая доктрина Российской Федерации [Электронный ресурс]: одобрена распоряжением Правительства Российской Федерации от 31 августа 2002 г. № 1225-p. URL: https://legalacts.ru/doc/rasporjazheniepravitelstva-rf-ot-31082002-n-1225-r/(дата обращения: 17.06.2021).

\section{Информация об авторах | Author information}

RU Рынкова Светлана Анатольевна

${ }^{1}$ Новосибирский государственный педагогический университет

EN Rynkova Svetlana Anatolievna ${ }^{1}$

${ }^{1}$ Novosibirsk State Pedagogical University

${ }^{1}$ nakmetod@mail.ru

\section{Информация о статье | About this article}

Дата поступления рукописи (received): 20.05.2021; опубликовано (published): 15.09.2021.

Ключевые слова (keywords): творческая активность; колледж; студенты; внеурочная деятельность; программы дополнительного образования; creative activity; college; students; extra-curriculum activity; additional educational programs. 